J. Egypt. Soc. Parasitol. (JESP), 51(3), 2021: 539 - 550

(Online: 2090-2549)

\title{
COMPARISON BETWEEN THE EFFECTS OF MAGNESIUM OXIDE (MGO) NANO-PARTICLES AND MICROWAVES (MVS) IRRADIATION ON GIARDIA LAMBLIA CYSTS
}

By

EMAN M. HUSSEIN ${ }^{1}$, ABDALLA M. HUSSEIN ${ }^{2}$, FARID EL-TANTAWY ${ }^{3}$, AMIRA B. MOKHTAR ${ }^{1}$, OLA A. ISMAIL ${ }^{1}$, EMAN K. EL-GAYAR ${ }^{1}$, WAFAA M. ZAKI ${ }^{1}$, REHAB I. ALI ${ }^{4}$ AND ASHRAF G. TEMSAH ${ }^{5 *}$

Department of Medical Parasitology, Faculty of Medicine, Suez Canal University ${ }^{1}$, 41522, Ismailia, Department of Physics, Faculty of Science, Al-Azhar ${ }^{2}$, University, Cairo, Department of Physics, Faculty of Science, Suez Canal University ${ }^{3}$, Department of Pathology, Faculty of Medicine Suez Canal University ${ }^{4}$, and Department of Medical Parasitology, Faculty of Medicine, Al-Azhar, University ${ }^{5}$ Damietta Branch,

Egypt ( ${ }^{*}$ Correspondence: ashraftimsah_1@yahoo.com)

\section{Abstract}

The efficiency of the transmission of Giardia lamblia is assured by the presence of a cyst wall, which provides resistance to drastic osmotic and $\mathrm{pH}$ variations. Both magnesium oxide $(\mathrm{MgO})$ nanoparticles (NPs) and microwaves (MVs) are known to inactivate many microorganisms.

This study compared the effects of MgO NPs \& MVs irradiation on Giardia lamblia cysts in experimental mice as to treated and un-treated cysts viability, excystation, ultrastructure changes and infectivity.

The results showed that the $G$. lamblia cysts count were reduced to $\left(\mathrm{LD}_{90}\right)$ after $8,16, \& 24 \mathrm{hrs}$ of exposure to doses $100,50, \& 25 \mathrm{mg} / \mathrm{ml}$, respectively, while reduction rate of $\left(\mathrm{EC}_{50}\right)$ after 8 , $16, \& 24 \mathrm{hrs}$ of exposure to dose $50,25, \& 12.5 \mathrm{mg} / \mathrm{ml}$, respectively. MVs $\mathrm{LD}_{90}$ efficacy on cysts was detected after 30 seconds while $\mathrm{EC}_{50}$ after 20 seconds. Failure of excystation was $90 \%$ and 98\% among MgO NPs and MVs treated cysts. MgO NPs treated cysts showed multiple cytoplasmic vesicular vacuoles while the cyst wall appeared destructive with the release of the cytoplasm outside. MVs treated cysts were filled with one big vesicular vacuole with an increase in size while some contents were decreased in size and others disappeared completely. The infectivity rate among mice inoculated with $\mathrm{MgO}$ NPs and microwave treated cysts was $33.3 \%$ \& 8.2 $\%$ with a mild histopathological changes, with significant differences.

Keywords: Mice, Giardia lamblia, MgO NPs, Microwave, Infectivity, Viability, Ultrastructure.

\section{Introduction}

Giardia lamblia $(=G$. duodenalis or $G$. intestinalis) infects about 280 million people worldwide, mainly in developing countries with poor hygienic conditions (CDC, 2011). Prevalence rates were $20-30 \% \& 2-5 \%$ in developing and developed countries, respectively (Thompson, 2000), and major cause of childhood diarrhea (Nkrumah et al, 2011) Giardia life cycle includes motile trophozoites that parasitized the small intestine upper part and in response to appropriation, trophozoites differentiated into dormant resistant thick walled cysts in the lower part that surv ive outside the host and maintain transmission cycle by fecal-oral route (Upcroft and Upcroft, 2001). The contaminated water and food with the cysts is another way of spread- ing even with $<10$ cysts (Cernikova et al, 2018). El Shazly et al. (2007) in Egypt reported that potable water samples were contaminated with zoonotic protozoa of cryptosporidiosis and giardiasis were the pre-dominant ones. Giardia cyst wall resisted physical and chemical disinfectants (Arguello-Garcia et al, 2004). Giardiasis causes acute and/or chronic diarrhea with gastrointestinal symptoms (Feng and Xiao, 2011). Most giardiasis infected children have no symptoms at all, but few suffered from abdominal pain and watery, foul-smelling diarrhea that can lead to dehydration, also have excessive gas and bloating and could have a poor appetite, leading to weight loss, and uncommon fever. These symptoms begin 7 to 14 days after exposure to Giardia infection and may last, 
without treatment, for up to 4 or 6 weeks (CDC, 2018).

In giardiasis the majority of drugs acted on the trophozoites to treat the patients, but infective viable cysts continuously were excreted in stools during treatment (Gardner and Hill, 2001). Effective anti-giardiasis have been intense, but recurrent infections, virulence factors, and drug resistance-imposed the effective treatment (Cernikova et al, 2018). $G$. lamblia genotyping showed that assemblages A \& B were the commonest zoonotic ones (Feng and Xiao, 2011). However, both are completely different in variant-specific surface protein (VSP) gene (Laishram et al, 2012). Besides, in mice assemblage- $A$ induces minimal infection and cleared before establishing, but assemblage B readily infects them (Ankarklev et al, 2010). Also, both assemblages differed in rate of in-vitro growth, encystation, biochemical activities, symptoms, susceptibility to RNA Giardia parasite, and epidemiologic characteristics (Karanis, 1998; Plutzer et al, 2010).

Synthesis, characterization, and exploration of materials in nanometer region (1-100 $\mathrm{nm})$ generally confers larger surface areas compared with macro-sized ones by nanotechnology that enhanced their physicochemical and biological properties in food processing (Yadav, 2013). Large-scale one-dimensional magnesium oxide $(\mathrm{MgO})$ nanowires with $6 \times 10 \mu \mathrm{m}$ have been successfully synthesized and studied (Al-Hazmi et al, 2012). Although several anti-Giardia NPS in-vitro and in-vivo showed different validities degrees (Al-Mohammed et al, 2021), yet MgO has some advantages to other metals such as non-mutagenic effect, good stability, biologically synthesized in normal component of human body (Tang and Ly, 2014).

Microwaves (MVs) radiation is now popular in food industry for thawing drying, baking and inactivating microorganisms in foods with less heating and less food exposure to destructive (Rosenberg and Bögl, 1987). MV heating inactivates many pathogens as gram-positive and negative bacteria, viruses, parasites, and fungi (Rougier et al, 2014; Woo et al, 2000; Franssen et al, 2019). The major advantages of MVs in food industry were rapid heat transfer, selective heating, compactness of equipment, speed of switching on, and pollution-free without products of combustion that made using MVs whether thermal or non-thermal for soil disinfection (Yarahmadi et al, 2016). But, MVs as a household machine may be used as an alternative way for decontamination of food and water (Graczyk et al, 2007). Thus, treatment of infected hosts with NPs killed zoonotic infective stage (Idan and Ardalan, 2020).

This study aimed to evaluate the effects of $\mathrm{MgO}$ NPs \& MVs radiation in treating Giardia lamblia cysts viability, excystation, and infectivity.

\section{Materials and Methods}

Source of G. lamblia cysts: Fecal samples obtained from 9 school children heavily infected with G. lamblia as shown by abundant cysts in their stools and negative to other parasites were selected from the attendances of the pediatrics clinic in Suez Canal University to be the source of G. lambilia cyst in this study. Parasite in the patients' stool was genotyped assemblage B as a part of a genotyping study for Giardia (Hussein et al, 2017). This study was conducted from January to December 2019. The stool samples were immediately processed within 1-10 hours after excretion.

G. lamblia cysts isolation, concentration, and purification: Stools were mixed thoroughly with an equal volume of distilled water and the suspension was filtered on a sieve of 4 gauze layers to remove coarse materia1s. Then, the filtrate was centrifuged at $800 \mathrm{~g}$ for $5 \mathrm{~min}$., the deposit was re-suspended in distilled water and washed 3 times (Alvarado and Wasserman, 2006). A sucrose solution of 1.18 density was prepared $(455 \mathrm{~g}$ sucrose in $355 \mathrm{ml}$ distilled water), and then a sucrose solution of 1.9 density was prepared by mixing a known volume sucrose solution 1.18 density in an equal volume of distilled water. In a round bottom test tube, the two 
different sucrose gradients were introduced carefully without mixing them up. About $1 \mathrm{ml}$ of stool suspension was poured on the surface of the test tube containing sucrose solution was centrifuged at $600 \mathrm{~g}$ for $10 \mathrm{~min}$. The G. lamblia cysts were aspirated with a Pasteur pipette from the interface between the two gradients. Purified cysts were re-suspended in distilled water and stored at $4^{\circ} \mathrm{C}$ with antibiotics (Penicillin ${ }^{\circledR}$ and Streptomy$\operatorname{cin}^{\circledR}, 1,000$ units and $1 \mathrm{mg} / \mathrm{ml}$, respectively) for a maximum of 3 days before use (Mohsen and Abdel Hamid, 1993). These cysts were used for in vitro and in vivo studies.

Giardia lamblia cysts in-vitro MgO NPs experiments: The large-scale one-dimensional $\mathrm{MgO}$ nanowires with diameters of $6 \mathrm{~nm} \mathrm{x}$ lengths of $10 \mu \mathrm{m}$ and a surface area of about $461 \mathrm{~m} 2 / \mathrm{g}$, were successfully synthesized and prepared (Al-Hazmi et al, 2012). The doses ranged from $3,6.25,12.5,25,50, \& 100 \mathrm{mg}$ were incubated with Giardia cysts in a Pyrex test tube ( $1 \mathrm{ml}$ of purified viable 1X 105 cysts) at $37^{\circ} \mathrm{C}$ in PBS (PH 7.2) and examined 3 times daily until reached to the lethal dose. For each experiment, the activity was determined against time viable cysts counts were studied.

MVs irradiations: By placing three Petridishes containing $1 \mathrm{ml}$ of purified viable (1X 105) cysts previously washed three times by BPS. MV energy disintegration was done with Panasonic MVs (915 MHz) at $1000 \mathrm{~W})$ and applied at 5. 15, 30, 45, \& 60 seconds, respectively. Three experiments/time exposure were used (Hussain, 2015).

Assessment of Giardia cyst viability invitro: It was done by using trypan blue vital dye $0.4 \%$ (Strober, 2015). Cyst exclusion of the dye means viability. The lethal concentration dose $\left(\mathrm{LD}_{90}\right)$ was defined as the lowest concentrations of $\mathrm{MgO}_{2}$ lethal to $90 \%$ of cysts after exposure and effective concentration $\left(\mathrm{EC}_{50}\right)$ was defined as median effective concentrations of $\mathrm{MgO}_{2} \mathrm{NPs}$ lethal to $50 \%$ cyst after exposures (Hussein et al, 2018). Viability of cyst $/ \mathrm{ml}$ was calculated before and after microwaving (Escobedo and Cim- erman, 2007). The cytocidal effect ( $\left.\mathrm{IC}_{90}\right)$ was defined as lowest time of MV exposure lethal to $90 \%$ Giardia cyst was confirmed by a non-stained cyst. Inhibitory concentrations $\left(\mathrm{IC}_{50}\right)$ were defined as lowest time of MV exposure lethal to $50 \%$ Giardia cyst. In addition, encystation of the cysts were assessed, and the number of cysts in each group at each indicated time was determined from the representative three culture tubes.

TEM: Treated and non-treated cysts were examined for any changes in the wall, morphology, \& ultrastructure (Speer et al, 1979). One $\mathrm{ml}$ of each treated cyst with lethal dose and non-treated cysts were washed twice in $0.1 \mathrm{M}$ sodium cacodylate buffer $(\mathrm{pH}$ 7.2) with 5\% sucrose. Each sample was fixed in the following fixatives: $1 \%$ glutaraldehyde in $0.1 \mathrm{M}$ sodium cacodylate buffer ( $\mathrm{pH} 7.2)$ for $3 \mathrm{hrs}$, followed by two washes in the buffered $2 \%$ Osmium tetraoxide $\left(\mathrm{OsO}_{4}\right)$ in $1 \%$ Potassium Ferro-cyanide solution for one hr. and two washes in $0.5 \mathrm{M}$ sodium cacodylate buffer. After processing, slides were microscopic examined by Joel 1210 TEM.

Excystation rate: One ml containing $1 \times 10^{5}$ of purified G. lamblia cysts suspension incubated in $0.1 \mathrm{M}$ potassium phosphate $(\mathrm{pH}$ 7.0) \& $0.3 \mathrm{M}$ sodium bicarbonate for $30 \mathrm{~min}$ at $37^{\circ} \mathrm{C}$ in culture tubes. Cysts treated with $\mathrm{MgO}_{2}$ and $\mathrm{MV}$ irradiation $\mathrm{LD}_{90}$ were incubated separately for 30 minutes in bicarbonate then for $1.5 \mathrm{hrs}$ at $37^{\circ} \mathrm{C}$ in culture medium (TYI-S-33) after Ward et al. (1997).

For induction of excystation, assessment of total, partial, or failure excitation was determined by counting the cysts treated compared to cysts untreated using a hemocytometer under the microscope.

In vivo experiments: For assessment of the infectivity of treated cysts, 3 groups of $G$. lamblia infected (A, B \& C) of 6-week-old Albino mice (12/each) were intra-esophageal inoculated with $5 \times 103$ cysts. GA \& GB were inoculated with $\mathrm{MgO}_{2} \& \mathrm{MV} \mathrm{LD}_{90}$ doses, respectively while GC was inoculated with non-treated cysts. Besides, twelve heathy mice were used as control. Cysts output 
was counted by fecal stool examinations of Logul's iodine stained smears daily up to 12 days post-infection (PI). Mice were put individually in separate cages and feces excreted over $2 \mathrm{hrs}$ was collected. Scoring of infection intensity was estimated by counting cysts $/ 10$ high power fields (HPF) and 1-5 $(1+)=$ mild infection, $6-10(2+)=$ moderate infection, and $>10$ cysts $(3+)+$ heavy infection (Qin et al, 2020).

Histopathological examination: Gradings were after Williamson et al. (2000). Grade 0: Majority of villi architecture and epithelium cells was normal and villous/ crypt ratio about 3:1. Grade I: Most villi were finger-shaped, little broadened due to edema or mi-ld plasma cell infiltration. Epithelium of so-me villi usually with nuclear shifted from basal to cell superficial part, vesiculation in basal part, and infiltration of a few lymphocytes. Crypts normal and villous/crypt ratio was 2.5:1. Grade II: Most of villi had broadened, shortened, and heavy infiltration predominately plasma cells. Epithelium was often cuboidal disorganized by a lymphocytic infiltrate and sometimes marked vesiculation. Crypts length and villous/crypt ratio was 2:1. Grade III: Villi fused or bow-shaped with a heavy infiltrate in lamina propria, and epithelial changes similar to Grade II. Villous/crypt ratio was 1.5:1. Grade IV: Mucosa almost flat except for some indentations and crypts opened into surface. Epithel ium was heavily infiltrated and disorganized. Crypts had numerous mitosis and occasional crypts abscess.

Statistical analysis: $\mathrm{IC}_{50} \& \mathrm{IC}_{90}$ were evaluated (drug concentration in X-axis \& inhibition percentage in $\mathrm{Y}$-axis) using office $\mathrm{XP}$ (SDAS) software with linear regression as $\mathrm{M} \pm \mathrm{SD}$. ANOVA test (one-way analysis) and Chi-square/Fisher exact test were also used.

Significant levels were at $\mathrm{P}<0.05$. Cysts reduction and excystation rate were counted by following equation: Reduction rate/ excitation rate $=(a-b / a) \times 100 . a=$ mean number of intact/excyst cysts in control experiments, and $b=$ mean number of intact /excyst cysts in treated experiments.

Ethical approval: Verbal consent was obtained from the parents of patients, and all of the procedures were conducted according to the ethical standard approved by the Institutional Human Ethics Committee, Faculty of Medicine, Suez Canal University. All procedures related to animals were performed according to the ethical standards approved after Declaration of Helsinki (1964).

\section{Results}

In the present study, during $24 \mathrm{hrs}$ exposure to different doses of $\mathrm{MgO} \mathrm{NPs}$, in vitro, MgO NPs $\leq 6.25$ doses did not affect Giardia cysts. But, cysts count reduced to $90 \%$ (LD $\left.{ }_{90}\right)$ after $8,16, \& 24 \mathrm{hrs}$ of exposure to doses $10,50, \& 25 \mathrm{mg} / \mathrm{ml}$, respectively, but reduction rate reached $50 \%\left(\mathrm{EC}_{50}\right)$ after 8 , $16, \& 24 \mathrm{hrs}$ of exposure to dose 50,25 , \& $12.5 \mathrm{mg} / \mathrm{ml}$, respectively. As to MVs irradiation on Giardia cyst, $\mathrm{LD}_{90}$ for treated cysts was after 30 seconds, and $\mathrm{EC}_{50}$ was after 20 seconds as compared to control count $1 \times 105$ cysts, with significant differences

Reduction in excystation was $85 \%$ among cysts treated with MgO NPs LD90 while it was $98 \%$ in $\left(\mathrm{LD}_{90}\right) \mathrm{MV}$ treated cysts compared to $10 \%$ in the untreated control, with significant differences $(P=0.0001)$. Viable cyst was unstained while non-viable appeared stained blue by light microscopy.

TEM ultrastructure changes included size, shape, morphology, and appearance. Most of MgO NPs treated cysts were filled with multiple vesicular vacuoles that led to an increase in cell volume and size, but others were with decrease in cytoplasmic contents, lacerating cyst wall, with evacuated cellular material due to rupture. As to Giardia cysts the MV irradiations many changes were detected. Most of the treated cysts were filled with one vesicular vacuole that led to an increase in cell volume and size. Other contents decreased in size and shrinkage or sometimes disappeared completely with a small rim of granular cytoplasm surrounding cyst wall. 
In vivo infection rate in mice inoculated with $\mathrm{MgO}_{2} \quad \mathrm{NPs}$ treated cyst were $33.3 \%$ with mild degree pathological changes, and infectivity rate was $8.2 \%$ in mice inoculated with microwave treated cysts. In control, $91.8 \%$ infection rate with grade degree III of pathological changes was among mice inoc- ulated with untreated cysts, with significant differences. After 6-12 days of PI, stool analysis showed treated mice had a mild degree of infection intensity versus mice inoculated by untreated cysts that showed heavy infection intensity. Details were given in tables $(1,2,3, \& 4)$ and figures $(1,2, \& 3)$

Table 1: Counts of viable Giardia cyst after exposure to MgO NPs different doses as to time of exposure,

\begin{tabular}{|l|l|l|l|l|l|l|}
\hline \multirow{2}{*}{$\begin{array}{l}\text { Doses of } \\
\mathrm{MgO} 2 \mathrm{NPs}\end{array}$} & $8 \mathrm{hr}$. & \multicolumn{1}{l}{$16 \mathrm{hr}}$. & $24 \mathrm{hr}$. \\
\hline & Mean \pm S.D. & $\%$ & Mean \pm S.D. & $\%$ & Mean \pm S.D. & $\%$ \\
\hline $.6 .5 \mathrm{mg} / \mathrm{ml}$ & $99000 \pm 923.953$ & 1 & $98000 \pm 923.95$ & 2 & $90000 \pm 4619.764$ & 10 \\
\hline $12.5 \mathrm{mg} / \mathrm{ml}$ & $90000 \pm 4619.7$ & 10 & $80000 \pm 9239.52$ & 20 & $50000 \pm 18479.057$ & $50^{*}$ \\
\hline $25 \mathrm{mg} / \mathrm{ml}$ & $80000 \pm 4619.7$ & 20 & $50000 \pm 923.95$ & $50^{*}$ & $10000 \pm 1847.906$ & $90^{* *}$ \\
\hline $50 \mathrm{mg} / \mathrm{ml}$ & $50000 \pm 923.953$ & $50^{*}$ & $9833.33 \pm 705.6$ & $90^{* *}$ & $7000 \pm 923.953$ & 93 \\
\hline $100 \mathrm{mg} / \mathrm{ml}$ & $10000 \pm 923.953$ & $90^{* *}$ & $5000 \pm 923.9$ & 95 & $4000 \pm 923.953$ & 96 \\
\hline F, P. value & $443.390,0.000$ & $289.732,0.000$ & $289.732,0.000$ & \\
\hline
\end{tabular}

Control count $=1 \times 105$ cysts, with significant differences $*$ EC50, **LC90

Table 2: Effect of MVs Giardia cysts irradiation as to time exposures.

\begin{tabular}{|l|l|l|}
\hline Seconds & Mean \pm S.D. of viable cysts & $\%$ \\
\hline 10 & $99000 \pm 461.976$ & 1 \\
\hline 15 & $74366.66 \pm 115.507$ & 25 \\
\hline 20 & $50366.00 \pm 241.992$ & $50^{*}$ \\
\hline 25 & $31033.3 \pm 188.037$ & 70 \\
\hline 30 & $9966.6 \pm 465.046$ & $90^{* *}$ \\
\hline F, P. value & $27,918.331,0.000$ & Significant \\
\hline
\end{tabular}

Control count $=1 \times 105$ cysts, with significant differences *EC50, ${ }^{* *}$ LC90

Table 3: Excystation rate among MgO NPs \&MVs treated Giradia cysts compared to untreated.

\begin{tabular}{|l|l|l|l|l|l|l|}
\hline \multirow{2}{*}{} & Complete & \multicolumn{3}{l|}{ Partial } & Failure & \\
\cline { 2 - 7 } & Mean \pm S.D. & $\%$ & Mean \pm S.D. & $\%$ & Mean \pm S.D. & $\%$ \\
\hline MVs & $250 \pm 9.24$ & $0.13 \%$ & $1850 \pm 18.479$ & 1.87 & $98000 \pm 40.62$ & 98 \\
\hline MgO2 & $10500 \pm 461.97$ & $10 \%$ & $5000 \pm 561.9$ & 5 & $85000 \pm 459.61$ & 85 \\
\hline Untreated cysts & $90000 \pm 45.619$ & 90 & $7000 \pm 450.6$ & 7 & $3000 \pm 370.3$ & 3 \\
\hline F, P. value & $100,752.784,0.000$ & $116.943,0.000$ & $68,217.383,0.000$ \\
\hline
\end{tabular}

Significant differences

Table 4: Infectivity rates and grades of histopathology in mice infected with MgO NPs and MVs treated Giardia cysts compared to untreated. The differences were statistically significant

\begin{tabular}{|c|c|c|c|c|c|c|}
\hline & \multicolumn{2}{|c|}{ Infected } & \multicolumn{2}{|c|}{ No-infected } & \multirow[t]{2}{*}{ Total } & \multirow{2}{*}{$\begin{array}{l}\text { Fisher exact } \\
\text { p.value }\end{array}$} \\
\hline & No. & $\%$ & No. & $\%$ & & \\
\hline MVs & 1 & $8.2 *$ & 11 & 91.8 & 12 & \multirow{3}{*}{$\begin{array}{l}17.775 \\
0.00013\end{array}$} \\
\hline $\mathrm{MgO} 2$ & 4 & $33.4^{*}$ & 8 & 33.3 & 12 & \\
\hline Untreated cysts & 11 & $91.8 * * *$ & 1 & 8.2 & 12 & \\
\hline
\end{tabular}

\section{Discussion}

In the present in vitro study, G. lamblia cysts count reduced up to $90 \%\left(\mathrm{LC}_{90}\right)$ after $8,16, \& 24 \mathrm{hrs}$ of exposure to doses 100,50 , $\& 25 \mathrm{mg} / \mathrm{ml}$, respectively, and reduction rate reached $50 \%\left(\mathrm{EC}_{50}\right)$ after $8,16, \& 24 \mathrm{hrs}$ of exposure to dose $50,25, \& 12.5 \mathrm{mg} / \mathrm{ml}$, respectively.

This present data agreed with in agreement with the present study, as Chitosan (Cs) NPs at dose of $400 \mathrm{ug} / \mathrm{ml}$ after 180 minutes exposure killed all Giardia cysts (Yarahmadi et al, 2016). Whereas, Elmi et al. (2013) in Iran reported that Cs NPs was at $33.3 \%$ reduction rate of nanachitosan particles on Giardia cysts at dose of $50 \mathrm{ug} / \mathrm{ml}$ after 180 minutes exposure. On the other hand, Malekifard and Tavassoli (2020) in Iran found that Cs NPs had multiple cytotoxic effects in vitro and vivo. Gold (G) NPs is another metal that had $96 \%$ anti-Giardia cysts effect with a concentration of $0.3 \mathrm{mg} / \mathrm{ml}$ in 180 minutes (Buzea et al, 2007). Unfortunately, Gold NPs toxicity caused the in-vitro and in-vivo to damage several host tissues (Barathmanikanth et al, 2010; Abdelhalim et al, 2013). Subsequent- 
ly, Selenium (Se) and copper oxide $(\mathrm{CuO})$ NPs at concentrations $0.6 \& 0.3 \mathrm{mg} / \mathrm{ml}$ gave similar effects to metronidazole on Giardia cysts (Malekifard and Tavassoli, 2020). On the same time, Se NPs toxicity was contributed to the thyroid gland (Avery and Hoffmann, 2018), and slight-to-severe pathologic al lesions were found among animals (Whanger et al, 1996) and humans even with the sub-lethal doses (Urbankova et al, 2021). Nevertheless, CuO-NPs induced oxidative stress in human lymphocytes (Assadian et $a l, 2018$ ). Consequently, $\mathrm{MgO}_{2}$ is a normal component of the human body, so its toxicity was minimal when compared to other metals (Jin and He, 2011). $\mathrm{MgO}_{2}$ NPs triggered an inflammatory response via anti-apoptotic and antioxidant pathways, and simultaneously alter related hematologic factors particularly with the higher doses (Mazaheri et al, 2019). This toxicity was due to the small size and larger surface areas to volume ratio of NPs and thus, their biological reaction proved to be more than the bulk material (Lanone and Boczkowski, 2006). However, the nontoxic effects of NPs were reported in other studies (Buzea et al, 2007). The differences in anti-Giardia effect in the present study and others might be due to the origin of NPs themselves (Chithrani and Chan, 2007).

In the present study, the ultrastructure changes that occurred in Giardia cyst after incubation with $\mathrm{MgO}_{2} \mathrm{NPs} \mathrm{LD}_{90}$ were matched with several studies that reported the ability of $\mathrm{MgO}_{2} \mathrm{NPs}$ to deactivate several pathogens through the cell wall distortion (Jin and He, 2011; Rafiei et al, 2013). The ultrastructure changes shown in Cyclospora cayetanensis oocysts when incubated with the $\mathrm{MgO}_{2}$ NPs (Matica et al, 20017) were similar to that detected in the present study. The $\mathrm{MgO}_{2}$ NPs destructed the cyst wall barrier by the formation of reactive oxygen species that reacted with the carbonyl group in the peptide linkages in the parasite wall, leading to lipid peroxidation (Tang et al, 2020). Subsequently, destruction of the lipids and proteins of the membrane by $\mathrm{MgO}_{2}$ NPs led to increased permeability and flow of cytoplasmic contents out of the cell (Jin and He, 2011). Moreover, the strong electrostatic interaction between the cyst surface and the $\mathrm{MgO}_{2}$ NPs led to degradation of the protein (Xing and Bin-Fing, 2014), with the high $\mathrm{pH}$ (alkaline effect) that damaged the parasite's wall (Siles-Lucas et al, 2018)

In the present study, experimental results showed that the rate of infection among the mice inoculated with $\mathrm{MgO}_{2} \mathrm{NPs}$ treated cyst was $33,3 \%$ with a mild degree of histologic changes. Low histologic grade among mice inoculated with $\mathrm{LD}_{90}$ of $\mathrm{MgO}_{2} \mathrm{NPs}$ alternated DNA replication and protein synthesis of cysts during their penetration (Ramanujam and Sundrarajan, 2014). Thus, the ability of $10 \%$ viable cysts to induce infection was weak when compared to grade III in contro1s. In coordination with the present data, the oral administration of Cs NPs at the dose of $100 \mathrm{ug} / \mathrm{kg}$ reduced the mean of excreted cysts after 3 days up to 10 times in infected $G$. lamblia BALB mice (Chabra et al, 2019). Moreover, Cs NPs 50ug/Syrian hamster/day in combination with metronidazole significantly reduced the cysts and trophozoites counts from $63.3 \%$ to $94.6 \%$ (El-Gendy et $a l, 2012)$. With Giardia-infected rats treated with Curcumin NPs, the cysts and trophozoites count reduced to $54.6 \%$ \& $\% 51.7 \%$ respectively (Said et al, 2013). Silver (Ag) NPs alone reduced the Giardia cyst and trophozoites counted up to 72.7 and $81.1 \%$ in rats infected with Giardia lamblia after 8 days treatment while in combination with metronidazole, the effects reached $83.3 \%$ after 3 days treatment of infected BALBS mice while it was $66.6 \%$ after one day with Silver NPs treatment alone (Jarrell and Sener, 2003). Although, Ag NPs anti-Giardia effect was efficient and induced size-dependent cytotoxicity in human lung cells (Gliga et al, 2014). But, the combination of Zinc oxide NPs and metronidazole gave $100 \%$ lethal effect in experimentally infected mice and induced neurotoxicity among treated mice ((Brakat et al, 2019). The presence of infection among mi- 
ce in the present study may be referred to as the smallest infective dose (10 cysts) of giardiasis that matched with the count of completely excysted cysts among treated groups. Also, all of the previous in vivo work concerned the treatment of infected hosts with NPs and few studies involved on NPs effect on the cyst as the infective stage (Bavand et al, 2017).

In the present study, LD90 for treated cysts was demonstrated after 30 seconds while $\mathrm{EC}_{50}$ was shown after 20 seconds. The differences were statistically significant. At the same time, the infectivity rate was very low (8.2\%) among mice inoculated with MVtreated cysts. The present results were supported with other research as MVs were effective against multiple foods borne human parasites such as Cryptosporidium parvum (Duhain et al, 2012), Cyclospora cayetanensis (Ortega and Liao, 2006), Anisakis simplex (Vidaček et al, 2011). Microsporidium spores (Graczyk et al, 2007) and Heterophyes heterophyes encysted metacercaria (ElZawawy, 2008). MV irradiations were lethal to the microorganisms in the range of 1-350 $\mathrm{MHz}$ and the peak lethal effects were at 60 $\mathrm{GHz}$ (Leonelli and Mason, 2010; Carole et $a l, 2014)$. The ability of MVs to affect proteins is highly dependent on the bound water content of molecules. Absorbed energy is converted into heat energy within the medium resulting in increased temperature (Rosenberg and Bögl, 1987). However, sanitization of sewage sludge and solid waste landfill leachates by MVs radiation $<1000$ Watt was not efficient for inactivation of the $\mathrm{Gi}$ ardia lamblia cyst up to 7.5 minutes' exposure (Park et al, 2006), and it was significant in reduction of the cysts number with Mvs with 1000 watt (Graczyk et al, 2008). The controversy between the present result and the previous one may be due to the differences in the origin and size of samples used. As in the present study, only human samples with Giardia lamblia assemblage B were used, but animals may contaminate sewage sludge and solid waste landfill leachates sa- mples with all Giardia assemblages. In addition, MV was not effective against Toxoplasma gondii cysts (El-Nawawi et al, 2008). Although the destructive effect of thermal exposure by MV to the microorganism was the main, some bacteria had metabolic imbalance only after exposure (Mudhoo and Sharma, 2019). This explained the presence of $10 \% \mathrm{MV}$ treated cysts as viable by the dye and at the same time their abilities to excyst or to induce infection in the present which was very low.

In the present study, MV irradiations on Giardia cysts showed failure of excystation was $98 \%$ in $\mathrm{LD}_{90}$ treated cysts compared to $10 \%$ in untreated control, as well as multiple structures changes showed by TEM. Most of the treated cysts were filled with one vesicular vacuole, but other contents were decreased in size, and shrinkage and sometimes disappeared completely with a small rim of granular cytoplasm surrounding the cyst wa11. The reduction in number of viable Giardia cysts and ultrastructural changes agreed with Woo et al. (2000), they reported that the MV electromagnetic radiations that have a non-ionizing range with the high biological effects. Moreover, MV high thermal effect within the irradiating tissues and non-thermal effects in the absence of significant heating (Baniks et al, 2003), manifested at the cellular lvel (Morozov and Petin, 19980 particularly and partially at the molecular part; (Duhain et al, 2012). These effects were determined by the amount of penetrating and absorbed electromagnetic energy that is significantly converted into heat and other parts lead to the oscillation of ions and dipolar water molecules in tissue leading to irreversible destruction of the organisms (Rosenberg and Bögl, 1987; Yarahmadi et $a l$, 2016). The biophysical processes induced in the microorganisms or parasites by thermal and non-thermal effects led to denaturation of proteins, nucleic acids, or other vital components, as well as disruption of membranes (Melgunov et al, 2019). At the same time, MVs did not reduce the nutri- 
tional value of fresh vegetables such as vitamins and minerals any more than conventional cooking (Hoz et al, 2007; Duhain et al 2012). Although the MVs possessed the advantage of fast heating without any radioactivity (Pan et al, 2007), yet they require the technical expertise than the other methods of heating (Carole et al, 2014).

\section{Conclusion}

The excitation and infectivity rates were higher among cysts treated with $\mathrm{MgO}_{2} \mathrm{NPs}$ $(10 \%$ \& 33.4\%) than MV treated ones, but the intensity of infection and pathological grades were similar. Despite infectious doses of giardiasis $<10$ cysts but, treated cysts were hardly induce infection among mice. As to anti-Giardia effects, the microwave was superior to $\mathrm{MgO}$ NPs.

Author contributions: All authors equally contributed in this study.

Conflict of interest: The authors declare that they neither have any conflict of interest nor received fund

\section{References}

Abdelhalim, MNK, Abdelmottaleb, A, Moussa, SA, 2013: The gold nanoparticle size and exposure duration effect on the liver and kidney function of rats: In vivo. Saudi J. Biol. Sci. 20:177-81.

Al-Hazmi, F, Alnowaiser, F, Al-Ghamdi, AA, Al-Ghamdi, MM, Tuwirqi, A, et al 2012: A new large scales synthesis of magnesium oxide nanowires structural and antibacterial properties. Superlattices Microstructures 52, 2:200-9.

Al-Mohammed, HI, Albalawi, AE, Al Sadoun, H, Bakhitiari, N, Amraei, M, et al, 2021: Applying nanoparticles for treating Giardia infection: A systematic review. Int. J. Appl. Pharm. 13, 5:15-19.

Alvarado, A, Wasserman, M, 2006: Quick and efficient purification of Giardia intestinalis cysts from fecal samples. Parasitol. Res. 99:300-2.

Ankarklev, J, Jerlstrom-Hultqvist, J, Ringqvist, $\mathbf{E}$, Troell, $\mathrm{K}, \mathrm{Sv}, \mathrm{SG}, 2010$ : Behind the smile: Cell biology and disease mechanisms of $\mathrm{Gi}^{-}$ ardia species. Nat. Rev. Microbiol. 8:413-22.

Arguello-Garcia, R, Cruz-Soto, M, RomeroMontoya, L, Ortega-Pierres, G, 2004: Variability and variation in drug susceptibility among Giardia duodenalis isolates and clones exposed to 5-nitroimidazoles and benzimidazoles in vitro. J. Antimicrob. Chemother. 54: 711-21.

Assadian, E, Zarei, MH, Gilani, AG, Farshin, M, Degampanah, H, et al, 2018: Toxicity of copper oxide $(\mathrm{CuO})$ nanoparticles on human blood lymphocytes. Biol. Trace Elem. Res. 184: 350-7.

Avery, JC, Hoffmann, PR, 2018: Selenium, selenoproteins, and immunity. Nutrients 10: 1203. Doi: 10.3390/nu10091203

Baniks, S, Bandyopadhy, S, Ganguly, S, 2003: Bio-effects of microwave: A brief review. Bioresour. Technol. 87:155-9.

Barathmanikanth, S, Kalishwaralal, K, Sriram, M, Pandian, SRK, Hyung-Seop, Y, H, et al, 2010: Anti-oxidant effect of gold nanoparticles restrains hyperglycemic conditions in diabetic mice. J. Nanobiotechnol. 8:16. Doi: 10.1186/ 1477-3155-8-16.

Bavand, Z, Gholami, S, Honari, S, Rahimi, E B, Torabi, N, et al, 2017: Effect of gold nanoparticles on Giardia lamblia cyst stage in vitro. Arak Med. Univ. J. 16:27-37.

Brakat, RM, Sharaf El-Deen, SA, Abd-Elhafiz HI, 2019: Zinc oxide nanoparticles kill $G i$ ardia species and protect against intestinal damage. Egypt. J. Med. Microbiol. 28:95-103.

Buzea, C, Pacheco, II, Robbie, K, 2007: Nanomaterials and nanoparticles: sources and toxicity. Biointerphases 2, 4:MR17-71.

CDC, 2011: Giardiasis case definition. Atlanta, GA: US Department of Health and Human Services, At http://wwwn.cdc.gov/nndss/script/ casedef. aspx?CondYrID=685\&DatePub $=1 / 1 / 2011$ CDC, 2018: Giardiasis NNDSS Summary Repo rt for 2018. https://www.cdc.gov/healthywater/s urveillance/giardiasis/giardiasis-2018.html\#: :te $\mathrm{xt}=$ Giardiasis $\% 20 \mathrm{is} \% 20 \mathrm{a} \% 20$ nationally $\% 20$ noti fiable,local $\% 20$ or $\% 20$ state $\% 20$ health $\% 20$ depart ments

Cernikova, L, Faso, C, Hehl, AB, 2018: Five facts about Giardia lamblia. PloS Path. 14, 9: e1007250. Doi: 10.1371/journal.pp.1007250.

Chabra, A, Rahimi-Esboei, B, Habibi, M, Monadi, T, Azadbakht, M, et al, 2019: Effects of some natural products from fungal and herbal sources on Giardia lamblia in vivo. Parasitology 146:1188-98.

Chithrani, BD, Chan, WC, 2007: Elucidating the mechanism of cellular uptake and removal of protein-coated gold nanoparticles of different sizes and shapes. Nano Letters 7:1542-50. 
Duhain, GL, Minnaar, A, Buys, EM, 2012: Effect of chlorine, blanching, freezing, and microwave heating on Cryptosporidium parvum viability inoculated on green peppers. J. Food Prot. 75, 5:936-41.

El Shazly, AM, Elsheikha, HM, Soltan, DM, Mohammad, KA, Morsy, TA, 2007: Protozoal pollution of surface water sources in Dakahlia Governorate, Egypt. J. Egypt. Soc. Parasitol.37, $1: 55-64$

El-Zawawy, LA, 2008: Impact of several control measures on the encysted metacercariae of heterophyids, J. Egypt. Soc. Parasitol. 38, 3:94556.

El-Gendy, MA, Hammed, MP, Ghallab, M, Abdel Aziz, MO, Ibrahim, SM, 2021: Therapeutic effect of chitosan nanoparticles and metronidazole in treatment of experimentally giardiasis infected hamsters. Iran. J. Parasitol. 161: 32-42.

Elmi, T, Gholsmi, S, Fakhar, M, Azizi, F, 2013: A review on the use of nanoparticles in the treatment of parasitic infections. J. Mazand. Univ. Med. Sci. 23, 102:126-33.

El-Nawawi, FA, Tawfik, MA, Shaapan, RM, 2008: Methods for inactivation of Toxoplasma gondii cysts in meat and tissues of experimentally infected sheep. Foodborne Pathogol. Dis. 5, 5:687-90.

Escobedo AA, Cimerman S, 2007: Giardiasis: a pharmacotherapy review. Expert. Opin. Pharmacother. 8, 12:1885-902.

Feng, Y, Xiao, L, 2011: Zoonotic potential and molecular epidemiology of Giardia species and giardiasis. Clin. Microbiol. Rev. 24:110-40.

Franssen, F, Gerard, C, Cozma-Petruţ, A, Vieira-Pinto, M, Jambrak A, et al, 2019: Inactivation of parasite transmission stages: Efficacy of treatments on food of animal origin. Trends Food Sci. Technol. 83:114-28.

Gardner, TB, Hill, DR, 2001: Treatment of giardiasis. Clin. Microbiol. Rev. 14, 1:114-28.

Gliga, AR, Skoglund, S, Wallinder, IO, Fadeel, B, Karlsson, H, 2014: Size-dependent cytotoxicity of silver nanoparticles in human lung cells: The role of cellular uptake, agglomeration and Ag release. Part. Fib. Toxicol. 11:11. https: //doi.org/10.1186/1743-8977-11-11.

Graczyk, TK, Kacprzak, M, Neczaj, E, Tamang, L, Graczyk, H, et al, 2007: Human-virulent microsporidian spores in solid waste landfill leachate and sewage sludge, and effects of sanitization treatments on their inactivation. Par- asitol. Res. 101, 3:569-75.

Graczyk, TK, Kacprzak, M, Neczaj, E, Tamang, L, Graczyk, H, et al, 2008: Occurrence of Cryptosporidium and Giardia in sewage sludge and solid waste landfill leachate and quantitative comparative analysis of sanitization treatments on pathogen inactivation. Environ. Res. 106, 1: 27-33.

Hoz, A, Díaz-Ortiz, A, Moreno, A, 2007: Review on non-thermal effects of microwave irradiation in organic synthesis. J. Microw. Power Electromagn Energy 41:44-64.

Hussain, HT, 2015: Study the effect of microwaves radiation in the growth of some isolates fungi, J. Coll. Bas. Educ. 21, 89:173-84.

Hussein, EM, Ahmed, SA, Mokhtar, AB, Elzagawy, SM, Yahi, SH, et al, 2018: Antiprotozoal activity of magnesium oxide $(\mathrm{MgO})$ nanoparticles against Cyclospora cayetanensis oocysts. Parasitol. Inter. 67:666-674.

Hussein, EM, Ismail, OA, Mokhtar, AB, Mohamed, SE, Saad, RM, 2017: Nested PCR targeting intergenic spacer (IGS) in genotyping of Giardia duodenalis isolated from symptomatic and asympto- matic infected Egyptian School Children. Parasitol. Res. 1165:763-71.

Idan, EM, Ardalan, NM, 2020: Introducing silver nanoparticles as anti-giardial in experimentally infected mice: Therapy versus toxicity Sys. Rev. Pharm. 11, 4:701-8.

Jarrell, E, Sener, K, 2003: Potential drug targets in cyst-wall biosynthesis by intestinal protozoa: Drug resistance updates: Reviews and Commentaries in Antimicrobial and Anticancer Chemotherapy 6, 5:239-46

Jin, T, He, Y, 2011: Antibacterial activities of magnesium oxide $\left(\mathrm{MgO}_{2}\right)$ nanoparticles against food-borne pathogens, J. Nanoparticle Res.13: 6877-85.

Karanis, P, Ey, P, 1998: Characterization of axenic isolates of Giardia intestinalis established from humans and animals in Germany. Parasitol Res 84:442-9.

Laishram, S, Kang, G, Ajjampur, SSR, 2012: Giardiasis: A review on assemblage distribution and epidemiology in India. Indian J. Gastroenterol. 31, 1:3-12.

Lanone, S, Boczkowski, J, 2006: Biomedical applications and potential health risks of nanomaterials: Molecular mechanisms. Curr. Mol. Med. 6:651-63.

Leonelli C, Mason TJ, 2010: Microwave and ultrasonic processing: Now a realistic option for 
industry: Chemical engineering and processing. Process. Intensif. 49: 885-900.

Malekifard, F, Tavassoli, KV M, 2020: In vitro assessment antiparasitic effect of selenium and copper nanoparticles on Giardia deodenalis cyst. Iran. Soc. Parasitol. 15:411-47.

Matica, A, Menghiu, G, Ostafe, V, 2017: Toxicity of chitosan based products. New Front Chem. 26, 1:65-74.

Mazaheri, N, Naghsh, N, Karimi, A, Salavati, H, 2019: In vivo toxicity investigation of magnesium oxide nanoparticles in rat for environmental and biomedical applications. Iran. J. Biotechnol. Biotech. 17, 1:e1543. Doi: 10.21859/ ijb.1543.eCollection 2019 Jan

Melgunov, AN, Odoevsky, IM, Khrustalev, A V, Kurnosova OP, 2019: The Effect of microwave radiation on metacercaria of Opisthorchuis and larvae of Trichinella spiralis. Biol. Bull. 46, 3:251-7.

Mohsen, D, Abdel Hamid, M, 1993: Purification of Cryptosporidium oocysts and G. lamblia cysts using sucrose density gradients centrifugation. N. Egypt. J. Med. 9:888-9.

Morozov, II, Petin VG, 1998: Features of modifications of cytotoxic consequences of microwave and thermal heating. Radiatsionnaya Biol. Radioekol. 38:232-7.

Mudhoo, A, Sharma, SK, 2019: Microwave irradiation technology in waste sludge and wastewater treatment research. Crit. Rev. Environ. Sci. Technol. 41:999-1066.

Nkrumah, B, Nguah, SB, Nkrumah, B, et al, 2011: Giardia lamblia: A major parasitic cause of childhood diarrhea in patients attending a district hospital in Ghana. Parasit. Vectors 22, 4: 163

Nygard, K, Schimmer, B, Søbstad, Ø, Walde, A, Tveit, I, et al, 2006: A large community outbreak of waterborne giardiasis, delayed detection in a non-endemic urban area. BMC Public Health 6: 141. Doi: 10.1186/1471-2458-6-141.

Ortega, Y, Liao, J, 2006: Microwave inactivation of Cyclospora cayetanensis sporulation and viability of Cryptosporidium parvum oocysts. J. Food Prot. 69, 8:1957-60.

Pan, Y, Neuss, S, Leifert, A, Fischler, M, Wen, F, et al, 2007: Size-dependent cytotoxicity of gold nanoparticles. Small 3:1941-9.

Park, DK, Bitton, G, Melker, R, 2006: Microbial inactivation by microwave radiation in the home environment. J. Environ. Hlth. 69: 17-24. Quiz 39-40.
Plutzer J, Ongerth J, Karanis P, 2010: Giardia taxonomy, phylogeny, and epidemiology: Facts and open questions. Int. J. Hyg. Environ. Hlth. 213:321-3.

Rafiei, A, Roointan, ES, Samarbafzadeh, AR, Shayesteh, AA, Shamsizadeh, A, et al, 2013: Investigation of possible correlation between $\mathrm{Gi}$ ardia duodenalis genotypes and clinical symptoms in southwest of Iran. Iran. J. Parasitol. 8, 3: 389-95.

Raghupathi, KR, Koodali, RT, Manna, AC, 2011: Size-dependent bacterial growth inhibition and mechanism of antibacterial activity of zinc oxide nanoparticles. Langmuir. 5:4020-8.

Ramanujam, K, Sundrarajan, M, 2014: Antibacterial effects of biosynthesized $\mathrm{MgO}_{2}$ nanoparticles using ethanolic fruit extract of Emblica Officinalis. J. Photochem. Photobiol. 141:B296300.

Rosenberg, U, Bögl, W, 1987: Microwave pasteurization, sterilization, blanching, and pest control in the food industry. Food Technol. 41, 6: 92-9.

Rougier, C, Prorot, A, Chazal, P, Leveque, $P$, Leprat, P, 2014: Thermal and non-thermal effects of discontinuous microwave exposure (2.45 gigahertz) on the cell membrane of Escherichia coli. Appl. Environ. Microbiol. 80, 16:4832-41.

Said, EF, El Samad, LM, YM, 2013: Viability of silver, chitosan, and curcumin nanoparticles as anti-Giardia agents. Parasitol. Res. 111:545554.

Siles-Lucas, M, Casulli, A, Cirilli, R, Camena, D, 2018: Progress in the pharmacological treatm ent of human cystic and alveolar echinococosis: Compounds and therapeutic targets. PLoSNegl. Trop. Dis. 12, 4:e006422.

Speer, EC, Marchiondo, A, Mueller, B, Duszynski, W, 1979: Scanning and transmission electron microscopy of the oocyst wall of Isospora lacazei. Z. Parasitenkd. 59:219-25.

Strober, W, 2015: Trypan blue exclusion test for the cell viability. Current protocol in immunology 11: A3B 1-3.

Tang, Q, Jiang, X, Zhang, J, Wang, B, Liu, X, et al, 2020: Zinc oxide nanoparticles induce ferroptotic neuronal cell death in vitro and in vivo. Inter. J. Nanomed.15:5299-315.

Thompson, RC 2000: Giardiasis as a re-emerging infectious disease and its zoonotic potential. Int. J. Parasitol. 30: 1259-67.

Upcroft, P, Upcroft, A, 2001: Drug targets and 
mechanisms of resistance in anaerobic protozoa. Clin. Microbiol. Rev. 14, 1:150-64.

Urbankova, L, Skalickova, S, Pribilova, M, Ridoskova, A, Pelcova, P, et al, 2021: Effects of sub-lethal doses of selenium nanoparticles on the health status of rats. Toxics 9:28. https://doi. org/ 10.3390/toxics 9020028 .

Vidaček, S, De Las Heras, C, Solas, MIT, García, ML, Mendizábal, A, et al, 2011: Viability and antigenicity of Anisakis simplex after conventional and microwave heating at fixed temperatures. J. Food Prot. 74, 12:2119-26.

Ward, W, Alvarado, L, Rawlings, N, Engel, J, Franklin. C, et al, 1997: A primitive enzyme for a primitive cell: The protease required for excystation of Giardia. Cell 89:437-440.

Whanger, P, Vendeland, S, Park, YC, Xia, Y, 1996: Metabolism of sub-toxic levels of selenium in animals and humans. Ann. Clin. Lab. Sci.
26, 2:99-113.

Williamson A, O'Donoghue P, Upcroft P, 2000: Immune and patho-physiological response to different strains of $G$. duodenalis in neonatal mice. Int. J. Parasitol. 30:1259-67.

Woo, S, Rheeet, I, Park, H, 2000: Differential Damage in bacterial cells by microwave radiation on the basis of cell wall structure. Appl. Environ. Microbiol. 66,5:2243-7.

Xing, T, Bin-Fing, Lv, 2014: $\mathrm{MgO}$ nanoparticles as antibacterial agent: preparation and activity. Braz. J. Chem. Eng. 31:591-601.

Yadav, V, 2013: Nanotechnology, big things from a tiny world: A review, AEEE 3: 771-8.

Yarahmadi, M, Fakhar, M, Ebrahimzadeh, MA, Chabra, A, Rahimiesboei, B, 2016: The anti-giardial effectiveness of fungal and commercial chitosan against Giardia intestinalis cysts in vitro. J Parasit Dis 40:75-80.

\section{Explanation of figures}

Fig. 1: A \& B showed unstained viable and stained (non-viable) with Trypan blue X400.

Fig. 2: TEM of untreated and treated cyst; A: untreated cyst, long arrow showed intact cyst wall, short two arrows of two nuclei, and short and thick arrow showed white intra-cystic extra-cytoplasmic fluid. B: MgO NPs treated cyst containing two intra-cytoplasmic big vacuoles $\left(\begin{array}{l}1 \\ \& 2\end{array}\right)$ and injury of cell wall leads to leaking content inside cytoplasm (3), C: Injury of cyst wall in two sides with releasing of contents outside and highly vacuolated cytoplasm. D: Microwave treated cysts increase in size intact cell wall with decrease in thickness with big cytoplasmic vacuolated and shrinkages of content. E: Cyst treated with microwave showed cytoplasmic destruction into small peripheral fragments (two black arrows) and central part.

Fig. 3: A: Control negative of duodenal mucosa showed normal villous architecture with normal location of nuclei within lining columnar epithelium, sparse lymphocytes within stroma. B: small intestine of mice inoculated with untreated cyst showed duodenal mucosa with villous deformity \& hyperplastic elongated crypts in epithelium with frequent mitotic figures, lamina propria with marked inflammatory infiltrate formed mainly of neutrophils, some plasma cells and lymphocytes, some neutrophils attacked glands. C: MVs treated cyst infected mouse with histopathologic Grade 1 changes, villi finger like, with little oedema, lymphocytic infiltration (H\&E, X 400).

Fig. 3: D Mice inoculated with nano-treated grade 1: Duodenal mucosa showed blunting of villi and increased crypts. Cores of villi show mild inflammatory infiltrate. E: MVs treated mouse with grade I: Duodenal mucosa showed blunting of villi, lining epithelium with scattered nuclei transferred to more superficial location. Cores of villi with mild inflammatory infiltrate mainly of lymphocytes and plasma cells. F: Majority of $\mathrm{m}$ ice inoculated with microwave treated cysts $(98 \%)$, duodenal mucosa showed normal villous architecture, lining columnar epithelium with normal location of nuclei, sparse lymphocytes within stroma (H\&E X 400).

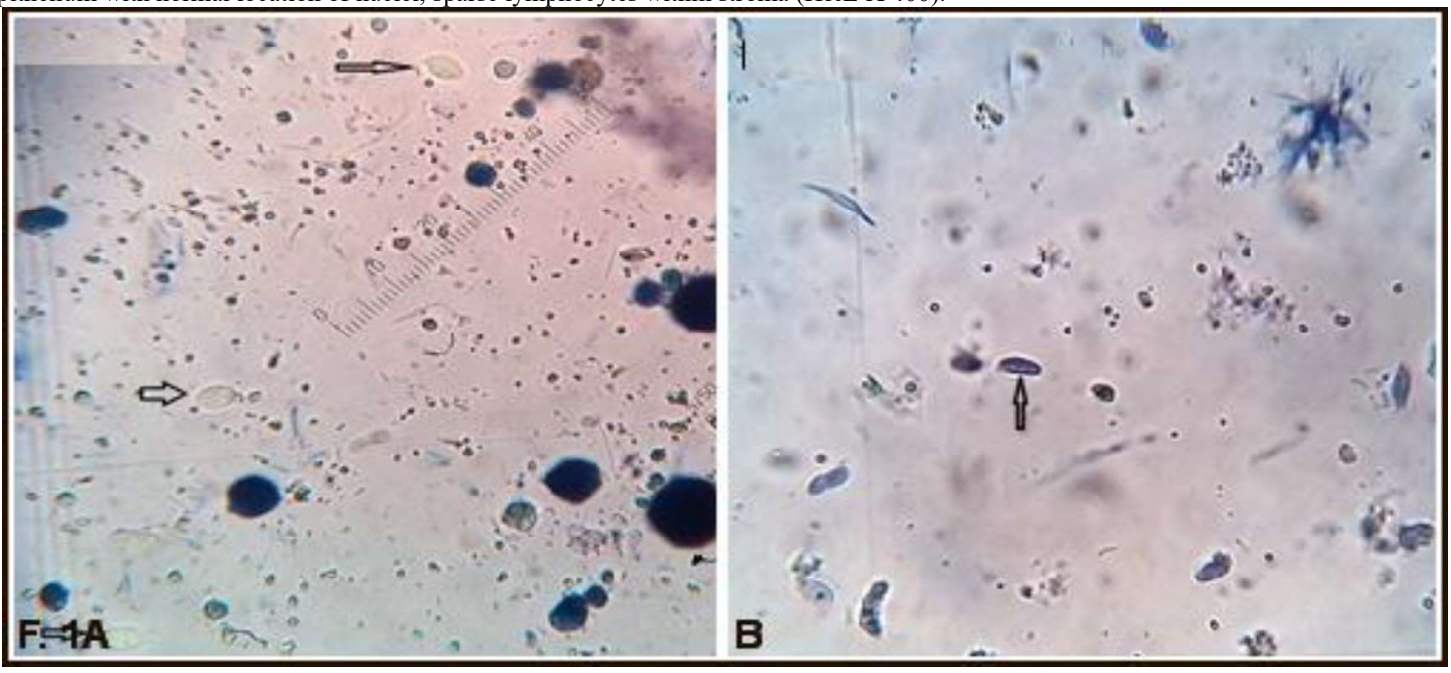



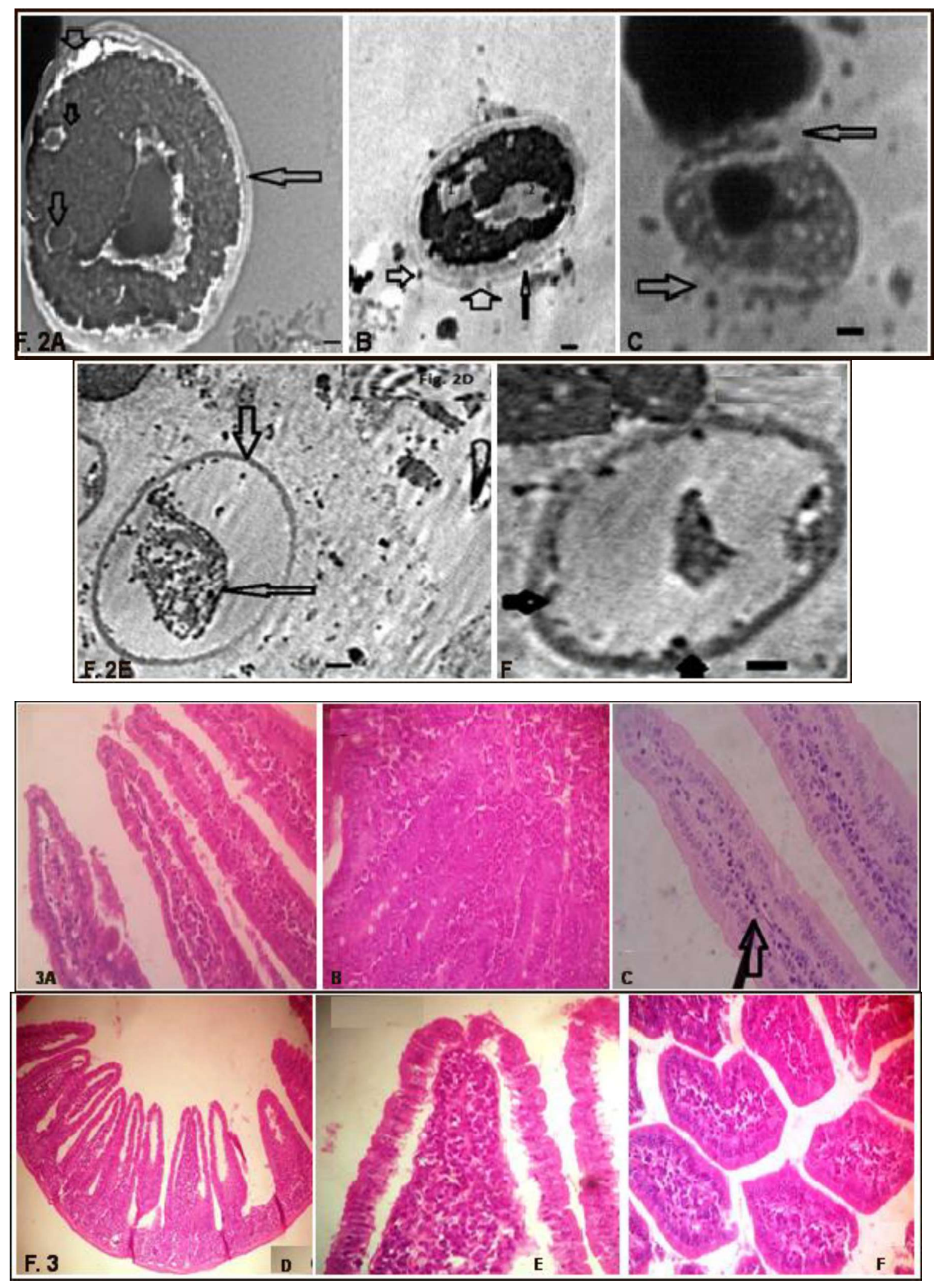